\title{
Farnesoid $X$ receptor represses hepatic human APOA gene expression
}

\author{
Indumathi Chennamsetty, ${ }^{1}$ Thierry Claudel, ${ }^{2}$ Karam M. Kostner, ${ }^{3}$ \\ Anna Baghdasaryan, ${ }^{2}$ Dagmar Kratky, ${ }^{1}$ Sanja Levak-Frank, ${ }^{1}$ Sasa Frank, ${ }^{1}$ \\ Frank J. Gonzalez, ${ }^{4}$ Michael Trauner, ${ }^{2,5}$ and Gert M. Kostner ${ }^{1}$
}

\begin{abstract}
${ }^{1}$ Institute of Molecular Biology and Biochemistry, Center of Molecular Medicine, and 2Laboratory of Experimental and Molecular Hepatology, Division of Gastroenterology and Hepatology, Department of Internal Medicine, Medical University of Graz, Graz, Austria. ${ }^{3}$ Department of Cardiology, University of Queensland, Mater Adult Hospital, Brisbane, Australia. ${ }^{4}$ Laboratory of Metabolism, National Cancer Institute, NIH, Bethesda, USA

${ }^{5}$ Division of Gastroenterology and Hepatology, Department of Internal Medicine III, Medical University of Vienna, Vienna, Austria.
\end{abstract}

\begin{abstract}
High plasma concentrations of lipoprotein(a) [LP(a), which is encoded by the APOA gene] increase an individual's risk of developing diseases, such as coronary artery diseases, restenosis, and stroke. Unfortunately, increased $L P(a)$ levels are minimally influenced by dietary changes or drug treatment. Further, the development of $L p(a)$-specific medications has been hampered by limited knowledge of $L p(a)$ metabolism. In this study, we identified patients suffering from biliary obstructions with very low plasma $L P(a)$ concentrations that rise substantially after surgical intervention. Consistent with this, common bile duct ligation in mice transgenic for human APOA ( $\operatorname{tg}-A P O A$ mice) lowered plasma concentrations and hepatic expression of APOA. To test whether farnesoid $X$ receptor (FXR), which is activated by bile acids, was responsible for the low plasma $\mathrm{LP}(\mathrm{a})$ levels in cholestatic patients and mice, we treated $\operatorname{tg}-A P O A$ and $\operatorname{tg}-A P O A / \mathrm{Frr}^{-/-}$mice with cholic acid. FXR activation markedly reduced plasma concentrations and hepatic expression of human APOA in $\operatorname{tg}-A P O A$ mice but not in $\operatorname{tg}-A P O A / \mathrm{Fxr}^{-/-}$mice. Incubation of primary hepatocytes from $\operatorname{tg}-A P O A$ mice with bile acids dose dependently downregulated $A P O A$ expression. Further analysis determined that the direct repeat 1 element between nucleotides -826 and -814 of the $A P O A$ promoter functioned as a negative FXR response element. This motif is also bound by hepatocyte nuclear factor $4 \alpha(\mathrm{HNF} 4 \alpha)$, which promotes $A P O A$ transcription, and FXR was shown to compete with $\mathrm{HNF} 4 \alpha$ for binding to this motif. These findings may have important implications in the development of $\mathrm{LP}(\mathrm{a})$-lowering medications.
\end{abstract}

\section{Introduction}

Lipoprotein(a) $[\mathrm{Lp}(\mathrm{a})]$ is a plasma lipoprotein found in humans and Old World monkeys but is absent in conventional laboratory animals. Plasma Lp(a) concentrations are under strict genetic control and range from less than $1 \mathrm{mg} / \mathrm{dl}$ to more than $200 \mathrm{mg} / \mathrm{dl}$, with medians of 8 to $9 \mathrm{mg} / \mathrm{dl}$ (reviewed in refs. 1,2). $\mathrm{Lp}(\mathrm{a})$ is a complex plasma lipoprotein formed through covalent binding of free APOA, which is synthesized predominantly in the liver, with apoB100 of low-density lipoprotein (3). Although it has been known for many years that elevated plasma $\mathrm{LP}(\mathrm{a})$ concentrations are associated with thrombo-atherogenic diseases (4-6), recent evidence from large cohorts has finally confirmed a causal relationship (7-11). Therefore, in a consensus report, the European Atherosclerosis Society recommended screening for $\mathrm{Lp}(\mathrm{a})$ in people at moderate to high risk of cardiovascular disease, in which the desirable cutoff for $\mathrm{Lp}(\mathrm{a})$ was set at less than $50 \mathrm{mg} / \mathrm{dl}$ (12).

The thrombo-atherogenic properties of $\mathrm{Lp}(\mathrm{a})$ have also been well documented in transgenic mice $(13,14)$. Several hemostatic pathways have been attributed to the pathomechanisms of Lp(a) $(15,16)$. Due to its high atherogenicity, several attempts were made to treat individuals with increased $\mathrm{Lp}(\mathrm{a})$ levels with either medication or diet (16), without success. Even though nicotinic acid and its derivatives lower Lp(a) levels by up to $30 \%$, they are not widely used due to frequent side effects. Therefore, to date, there is no safe drug available for the treatment of individuals with elevated plasma Lp(a) levels, and the development of new

Conflict of interest: The authors have declared that no conflict of interest exists. Citation for this article: J Clin Invest. 2011;121(9):3724-3734. doi:10.1172/JCI45277. drugs is hampered by a lack of detailed knowledge of both Lp(a) biosynthesis and catabolism.

Previous turnover studies in humans demonstrated that plasma Lp(a) levels strongly correlate with its rate of biosynthesis but not with the fractional catabolic rate $(17,18)$. Thus, any attempt to control plasma Lp(a) levels should focus on an interference with APOA biosynthesis. This has been supported by in vivo studies using antisense strategies in which plasma levels of an $\mathrm{N}$-terminal APOA fragment expressed in mice under the control of the CMV promoter were reduced to almost zero (19). However, small molecule medications are not yet available.

The farnesoid X receptor (FXR, also known as NR1H4) is a bile acid-activated receptor and belongs to the nuclear receptor superfamily of ligand-activated transcription factors (20-23). FXR is mainly expressed in the liver, intestine, kidney, and adrenal glands. FXR heterodimerizes with the retinoid X receptor ( $\mathrm{RXR} \alpha$; also known as NR2B1), binds to FXR response elements (FXREs) that are usually but not exclusively inverted repeat-1 (IR-1), and regulates transcription of target genes (24). A direct repeat (DR) with a similar core sequence is also compatible for binding of FXR, either as a monomer or heterodimer (24-27). FXR plays important roles in bile acid, cholesterol, lipoprotein, and triglyceride metabolism. Activation of hepatic FXR modulates the expression of many hepatic genes involved in lipid metabolism. Studies using $\mathrm{Fxr}^{-1-}$ mice have illustrated the importance of this nuclear receptor in maintaining cholesterol and bile acid homeostasis $(28,29)$.

In the present study, we report that transcription of the APOA gene is under strong control of FXR, which binds to a negative control element located at the -826 -bp region of the human $A P O A$ 


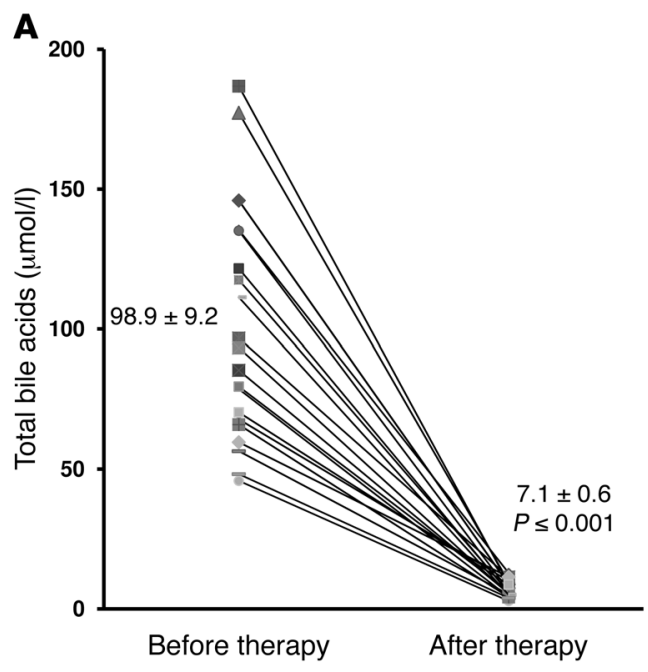

\section{Figure 1}

Low plasma Lp(a) levels in patients with obstructive jaundice. Plasma samples from 20 patients suffering from obstructive jaundice of different etiology were assayed for $(\mathbf{A})$ total bile acids and $(B) L p(a)$, before and after surgical or endoscopic treatment. Values are expressed as mean \pm SEM. See Supplemental Table 1 for details. promoter. FXR was found to interfere with the hepatocyte nuclear factor $4 \alpha$-mediated (HNF $4 \alpha$-mediated) (HNF $4 \alpha$ is also known as NR2A1) activation of $A P O A$ transcription.

\section{Results}

Elevated bile acid levels drastically reduce plasma Lp(a) levels in bumans. We consistently noticed in various clinical settings that patients suffering from obstructive jaundice exhibited very low or even undetectable levels of plasma Lp(a). To study this in a more systematic way, patients with obstructive jaundice were analyzed for markers of cholestasis, such as bilirubin, lipoprotein X (LP-X), and plasma bile acid concentrations, and the results were correlated with Lp(a) levels. Supplemental Table 1 (supplemental material available online with this article; doi:10.1172/JCI45277DS1) lists the results from 20 patients suffering from biliary obstruction due to pancreatic, gallbladder, or bile duct cancer. In addition, 1 patient with congenital biliary atresia and 5 patients with choledocholithiasis were included. All patients had elevated plasma bilirubin concentrations $(316 \pm 48 \mu \mathrm{mol} / \mathrm{l})$ and were positive for plasma LP-X $(370 \pm 47.7 \mathrm{mg} / \mathrm{dl})$. Notably, the patients had plasma total bile acid levels of $98.9 \pm 9.2 \mu \mathrm{mol} / 1$ that were more than 10 -fold higher when compared with those of healthy individuals (Figure 1A). In 13 out of 20 of these patients, the plasma Lp(a) concentrations before therapy were less than $1 \mathrm{mg} / \mathrm{dl}$, which is the detection limit of the particular assay. The remaining 7 patients had very low $\mathrm{Lp}(\mathrm{a})$ levels in relation to their $A P O A$ isoform (K-IV repeats). After successful surgical or endoscopic treatment of biliary obstruction, bilirubin, LP-X, and total bile acid levels were normalized, and Lp(a) concentrations rose significantly to levels that correspond to those of healthy controls with the corresponding APOA isoforms. Mean plasma $\mathrm{Lp}$ (a) levels were $2.7 \pm 1.1 \mathrm{mg} / \mathrm{dl}$ before therapy and $20.3 \pm 4.4 \mathrm{mg} / \mathrm{dl}$ after therapy (Figure 1B).

A cholestatic mouse model with elevated bile acid levels exhibits very low plasma and hepatic expression of APOA. To determine the effects of obstructive cholestasis on plasma levels and hepatic APOA expression, mice transgenic for human $A P O A$ (tg- $A P O A$ mice) and tg- $A P O A$ mice that were Fxr deficient (tg-APOA/Fxr ${ }^{-1}$ mice) were subjected to biliary obstruction by common bile duct ligation (CBDL) for 3 days. CBDL in tg-APOA mice resulted in significantly elevated serum liver enzymes (Supplemental Table 2), total bile acids, and bilirubin (Figure 2, A and B). The accumulation of endogenous bile acids in tg-APOA mice led to dramatic reduction of plasma APOA levels by $87 \%$ (Figure 2C) and of hepatic APOA mRNA expression by $98 \%$ (Figure $2 \mathrm{D}$ ). CBDL in tg-APOA $/ \mathrm{Fxr}^{-/}$mice showed a small but measurable reduction of plasma APOA by $15 \%$ and hepatic mRNA by 19\% (Supplemental Figure 1), which might be due to inflammation and hepatic injury. In conclusion, low APOA levels found in mouse and human cholestasis suggested that APOA expression is regulated by bile acids in vivo.

Cholic acid feeding reduces plasma APOA concentrations and hepatic APOA expression in transgenic APOA mice. To study regulation of the human $A P O A$ gene expression by bile acids in a non-cholestatic model, tg-APOA and $\operatorname{tg}-A P O A / \mathrm{Fxr}^{-1}$ mice expressing the human $A P O A$ gene were fed for 5 days with either a normal chow diet (control) or a chow diet supplemented with $0.2 \%$ cholic acid (CA) (w/w). No changes in body weight or food intake were observed between control and treated groups (data not shown). Plasma total cholesterol and triglyceride levels were reduced in $\operatorname{tg}-A P O A$ mice upon CA feeding but remained unchanged in $\operatorname{tg}-A P O A / \mathrm{Fxr}^{-/-}$mice (Supplemental Figure 2). A $0.2 \%$-CA supplementation led to a significant $72 \%$ decrease in plasma APOA levels in tg-APOA mice (Figure $3 \mathrm{~A}$ ). To evaluate whether the reduction of plasma APOA levels was due to decreased APOA mRNA levels in liver, real-time quantitative PCR analysis was performed. APOA mRNA levels were significantly decreased in the livers of the CA-fed tg-APOA mice (Figure $3 \mathrm{~B}$ ). Western blot analysis of liver homogenates confirmed that this repression also occurs at the protein level upon CA feeding in $\operatorname{tg}-A P O A$ mice (Figure 3C). In tg- $A P O A / \mathrm{Fxr}^{-1}$ mice, however, plasma APOA concentrations (Figure 3D), hepatic APOA mRNA levels (Figure $3 \mathrm{E}$ ), and protein levels (Figure $3 \mathrm{~F}$ ) were comparable in control and CA-treated mice. Taken together, these data indicate that both plasma levels and hepatic expression of human APOA are downregulated by CA feeding in $\operatorname{tg}-A P O A$ mice in an FXR-dependent manner.

Subsequently, we profiled hepatic expression of known FXR target genes involved in bile acid and cholesterol metabolism after a 5-day feeding of $\operatorname{tg}-A P O A$ and $\operatorname{tg}-A P O A / \mathrm{Fxr}^{-1}$ mice with CA (Figure $3, \mathrm{G}$ and $\mathrm{H}$ ). As expected, $\mathrm{CA}$ treatment of $\mathrm{tg}-A P O A$ mice led to a strong inhibition of both Cyp7a1 and Cyp8b1 (30-32), 2.3-fold upregulation of small heterodimer partner ( $\operatorname{sh}$, also known as NR0B2) (33), and induction of Bsep. No changes were observed in the hepatic mRNA expression of Lrb1 and Hnf4a. Fgf15 mRNA in the ileum was upregulated by 2.8 fold (34). CA feeding did not change hepatic expression of Cyp3a11, a target gene of pregnane $\mathrm{X}$ receptor 

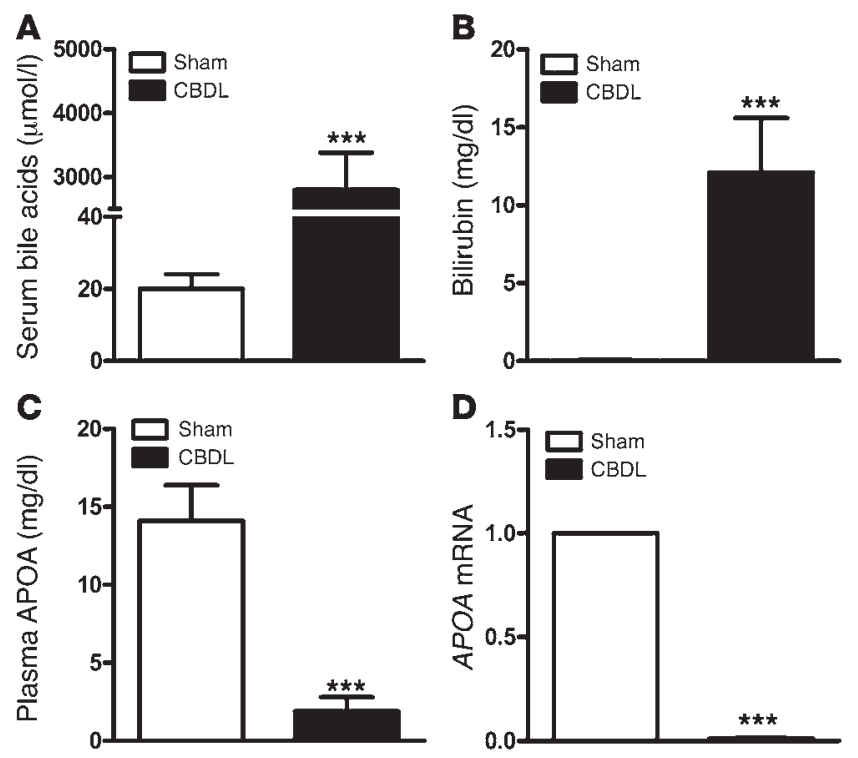

(PXR; also known as NR1I2) in tg-APOA mice, indicating that PXR was not activated by $0.2 \% \mathrm{CA}$ in the diet. In contrast, CA treatment had no impact on mRNA levels of FXR target genes in tg-APOA/ $\mathrm{Fxr}^{-1}$ - mice, yet Cyp3a11 expression was induced $(35,36)$.

Bile acids can induce inflammation in the liver and cause liver damage (37). Moreover, cholestasis in humans and mice is characterized by high inflammation (38). Therefore, we studied the hepatic expression of several proinflammatory genes. A $0.2 \%$-CA feeding did not change the expression levels of proinflammatory cytokines such as $I l 6, I l 1 b$, and Tnfa in tg-APOA mice (Supplemental Figure 3A), whereas Il6 expression was 2.6-fold increased in tg-APOA/Fxr ${ }^{--}$mice (Supplemental Figure $3 \mathrm{~B}$ ). Taken together, these results showed that bile acids repress $A P O A$ expression by an FXR-mediated mechanism.

$C A$ and GW4064 decrease buman APOA gene expression in primary hepatocytes. To further study the direct mechanism of the inhibitory effect of FXR on hepatic APOA expression, we then studied the influence of FXR agonists on APOA expression in mouse primary hepatocytes. For this purpose, primary hepatocytes were isolated from tg-APOA mice and incubated with different concentrations of the natural FXR ligand CA. Analysis of mRNA levels by real-time quantitative PCR revealed a significant dose- and time-dependent decrease in APOA transcript levels, suggesting a transcriptional effect (Figure 4, A and B). Western blot analysis confirmed that this CA-mediated repression also occurs at the protein level (Figure 4C). Cell viability was assessed with the trypan blue exclusion test, revealing that all concentrations of CA were well tolerated by the cells (data not shown).

Since bile acids may exert FXR-independent effects by activating other signal transduction pathways $(39,40)$, we additionally tested the influence of the synthetic nonsteroidal FXR agonist GW4064 on APOA gene expression. Treatment of primary hepatocytes with $5 \mu \mathrm{M}$ GW4064 for 24 hours resulted in a significant decrease of APOA mRNA (Figure 4D) and protein levels (Figure 4E) when compared with those of vehicle-treated control cells. In addition, we measured the expression levels of control FXR target genes after treatment with CA and GW4064 and found that both ligands increased Shp and markedly decreased Cyp7a1 and Apoa1 mRNA levels (Supplemental Figure 4, A and B).

\section{Figure 2}

Drastic reduction in plasma levels and hepatic mRNA expression of $A P O A$ in a mouse model of cholestasis. $\operatorname{tg}-A P O A$ mice were subjected to biliary obstruction by $\operatorname{CBDL}(n=3$ per group) or sham operation ( $n=4$ per group) for 3 days. (A and B) Total bile acids and bilirubin were measured in serum. Data are presented as mean \pm SD. ${ }^{* * *} P \leq 0.001$, when compared with sham-operated mice. (C) Plasma levels of APOA were measured by DELFIA and are expressed as mean \pm SD $\left({ }^{* * *} P \leq 0.001\right)$. (D) Liver APOA mRNA levels were analyzed by real-time quantitative PCR normalized to cyclophilin and are expressed relative to those of sham-operated mice. Results represent mean \pm SEM $\left({ }^{\star * \star} P \leq 0.001\right)$.

Overall, these results demonstrate that both natural and synthetic FXR agonists downregulate human APOA expression in cultured mouse primary hepatocytes via a transcriptional mechanism.

Mapping of an FXRE in the buman APOA promoter. To provide direct evidence for the FXR-mediated inhibitory effect on the APOA promoter and to further identify relevant promoter element(s), a $2-\mathrm{kb}$ fragment of human $A P O A$ promoter (from $-1,952 \mathrm{bp}$ to $+52 \mathrm{bp}$, referred to herein as $\mathrm{h} A P O A-1,952 /+52$ promoter) was cloned into pGL3-luciferase reporter plasmid (Figure 5A). In addition a series of $5^{\prime}$ deletion constructs were generated, as shown in Figure 5D. Transient transfections were performed in HepG2 cells with the $\mathrm{h} A P O A-1,952 /+52$ promoter construct in the absence or presence of FXR and FXR agonists. FXR alone resulted in a $29 \%$ decrease in promoter activity, and this effect was further enhanced by the addition of chenodeoxycholic acid (CDCA) (63\%) (Figure 5B). Likewise, incubation with FXR and GW4064 also strongly repressed the activity of the hAPOA $-1952 /+52$ promoter by $57 \%$ (Figure 5C). In the absence of FXR overexpression, the hAPOA -1952/+52 promoter was inhibited by $25 \%$ or less by CDCA or GW4064 alone. This decrease likely resulted from the activation of the endogenous FXR that is expressed in HepG2 cells (27).

To avoid endogenous FXR-mediated feedback inhibition, transient transfection experiments were performed in COS-7 cells, a nonhepatic cell line. Transfection of COS-7 cells in the absence or presence of FXR repressed the hAPOA $-1,952 /+52$ promoter activity by $24 \%$, an effect that was significantly enhanced by CDCA (43\%) (Supplemental Figure 5). These experiments demonstrated that ectopic expression of FXR and a physiological concentration of CDCA are required to repress the $A P O A$ promoter activity in nonhepatic cells.

Since $S h p$ was induced by CA treatment in vivo and in vitro, we subsequently studied the APOA promoter activity upon cotransfection of cells with increasing concentrations of a SHP expression plasmid. Surprisingly, SHP did not lower APOA promoter activity but further enhanced it (Supplemental Figure 6). Taken together, these results showed that FXR can regulate APOA promoter activity in a direct and SHP-independent manner.

Next, to identify promoter elements responsible for the observed effects of FXR, HepG2 cells were transfected with 5' deletion constructs of the human APOA promoter in the absence or presence of FXR and/or CDCA. Reduced promoter activities were noted for both the -1,446-bp and -857-bp constructs (Figure 5D). However, the repression was relieved for -757-, -657-, -477-, and -148-bp promoter constructs, indicating that the region between $-857 \mathrm{bp}$ to $-757 \mathrm{bp}$ of the human $A P O A$ promoter contains a potential negative FXRE, which might be responsible for the observed bile acid response.

Notably, in silico Matinspector promoter analysis (41) and NUBIScan algorithm (42) suggested the presence of a DR-1 element located between nucleotides -826 and -814 . Previous stud- 

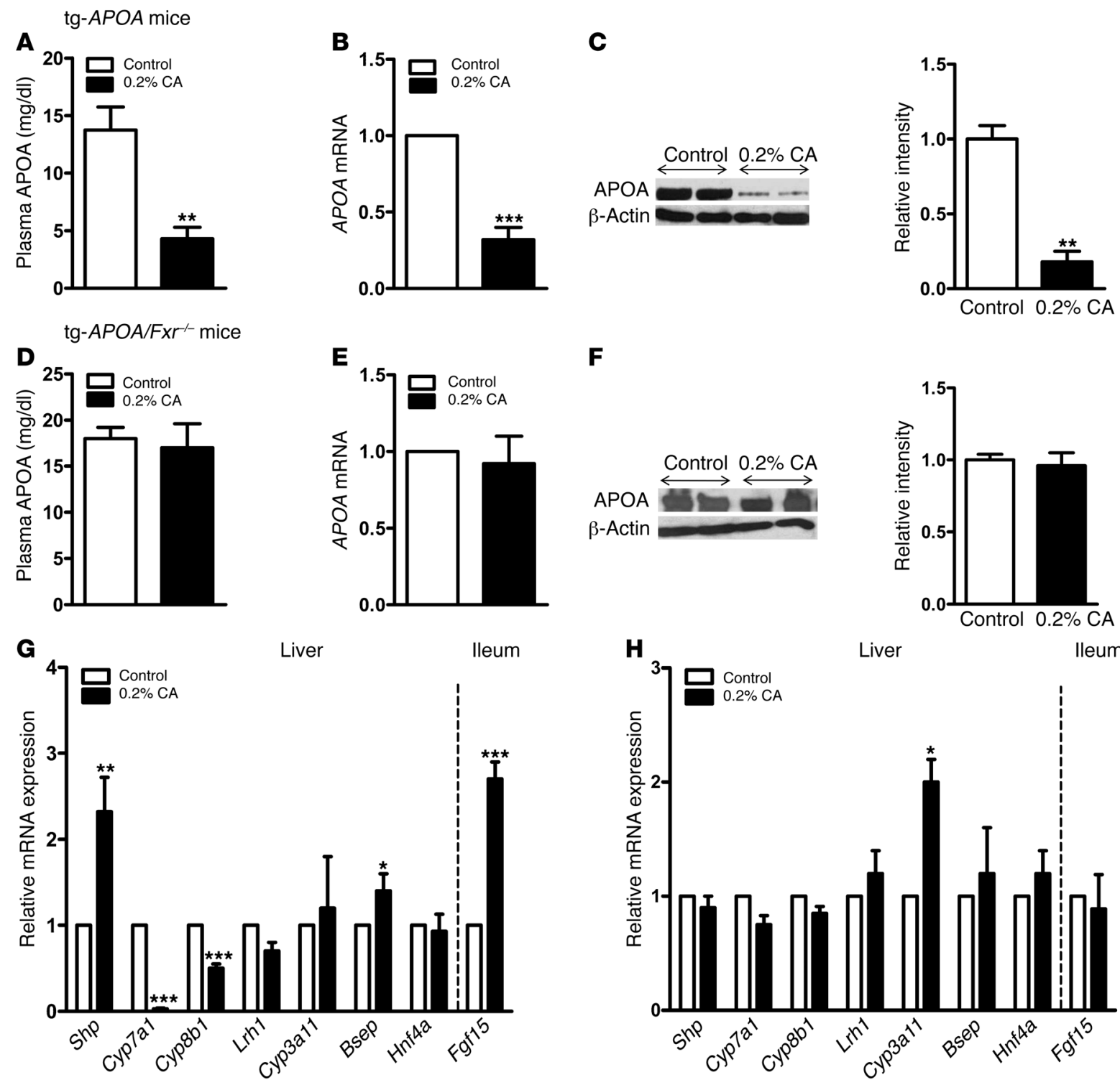

$\operatorname{tg}-A P O A$ mice

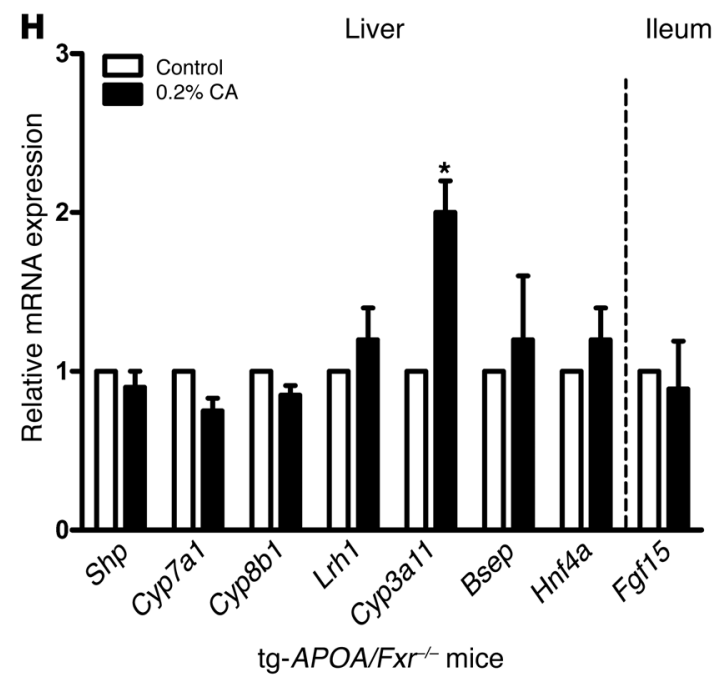

Figure 3

CA decreases plasma levels and hepatic expression of $A P O A$ in tg- $A P O A$ mice but not in tg- $A P O A / F x r^{-1-}$ mice. $\operatorname{tg}-A P O A$ mice $(n=8$ per group) and tg-APOA/Fxr-- mice ( $n=8$ per group) expressing human APOA were fed $0.2 \%$ CA (w/w) mixed in normal chow for 5 days. Control mice received normal rodent chow. (A and $\mathbf{D})$ Plasma levels of APOA were measured by DELFIA and are expressed as mean \pm SD $\left({ }^{\star \star} P \leq 0.01\right)$. (B and E) Mouse liver APOA mRNA levels were analyzed by real-time quantitative PCR and normalized to cyclophilin and are expressed relative to those of control mice. Results represent mean \pm SEM $\left({ }^{* * *} P \leq 0.001\right)$. (C and $\left.\mathbf{F}\right)$ Western blot analysis and densitometric quantification of APOA levels in the protein extracts from liver tissue (expressed as mean \pm SD relative to controls; ${ }^{* \star} P \leq 0.01$ ). The gene expression profile was analyzed in $(\mathbf{G}) \operatorname{tg}-A P O A$ mice and $(\mathbf{H}) \operatorname{tg}-A P O A / F x r^{-1}$ mice by real-time quantitative PCR. mRNA expression in control mice was arbitrarily set to 1 and normalized to that of cyclophilin. Results represent mean $\pm \operatorname{SEM}\left({ }^{* * *} P \leq 0.001,{ }^{* *} P \leq 0.01,{ }^{*} P<0.05\right)$.

ies have already shown that the DR-1 element can function as an FXRE $(24,43,44)$.

To test whether this DR- 1 site could mediate FXR-dependent repression of the $A P O A$ promoter, we introduced mutations in the context of the full-length hAPOA-1,952/+52 promoter (WT) and generated 2 mutant constructs (M1 and M2), as shown in Figure 5E. Mutation (M2) of this site completely abolished the FXR-mediated repression of $A P O A$ promoter activity (Figure $5 \mathrm{~F}$ ), indicating the binding of FXR to the second half site of the DR-1 element.
Taken together, these results suggest that the DR- 1 site, located between nucleotides -826 and -814 , is a negative response element via which FXR represses human $A P O A$ promoter activity.

FXR binds to the DR-1 site of the APOA promoter in EMSA. To provide additional evidence that the DR-1 element at the -826-bp region of the human $A P O A$ promoter can function as an FXRE, gel shift assays were performed. Consensus IR-1 probe was used as a positive control. FXR bound the labeled IR-1 probe both in the absence (Figure 6A, lane 3 ) and presence (Figure 6A, lane 4) of RXR. In contrast, 
A

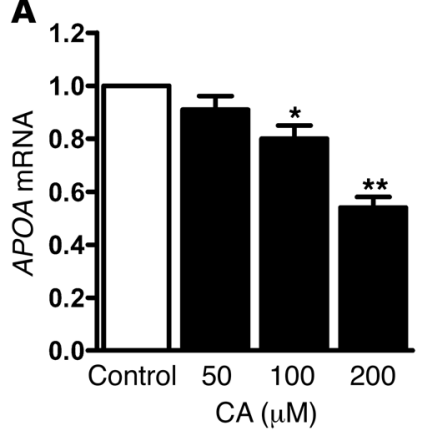

D

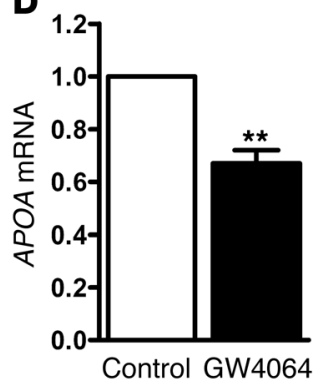

B

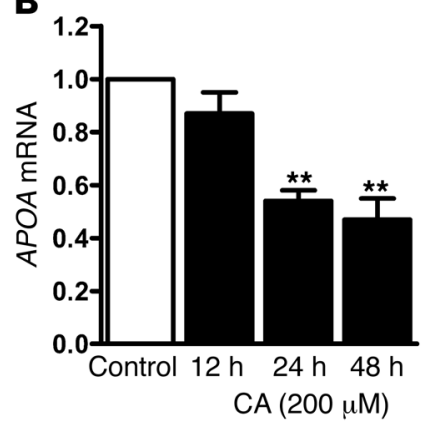

C

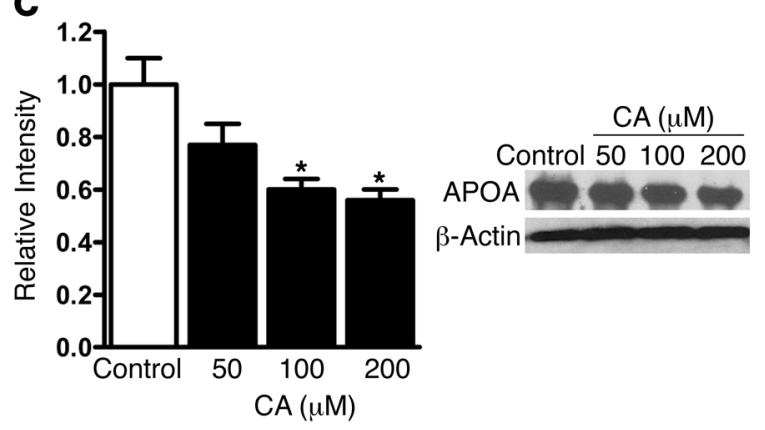

E

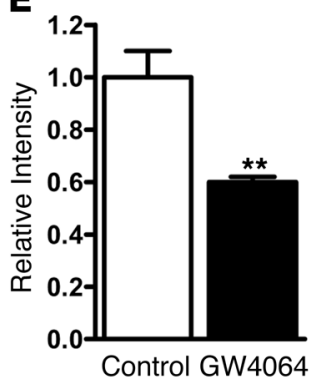

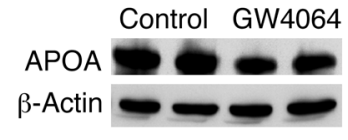

\section{Figure 4}

FXR agonists downregulate $A P O A$ gene expression in a dose- and time-dependent manner in primary mouse hepatocytes. (A) Primary mouse hepatocytes from tg-APOA mice were incubated with increasing concentrations of CA (50, 100, and $200 \mu \mathrm{M})$ or vehicle (control) for 24 hours. $A P O A$ mRNA levels were analyzed by real-time quantitative PCR. These data are presented as mean $\pm \mathrm{SEM}\left({ }^{\star *} P \leq 0.01,{ }^{*} P<0.05\right)$. (B) Primary mouse hepatocytes were incubated with CA $(200 \mu \mathrm{M})$ or vehicle for 12,24 , and 48 hours. APOA mRNA levels were measured by real-time quantitative PCR. Results represent mean \pm SEM of 3 independent experiments $\left({ }^{* *} P \leq 0.01\right)$. (C) Western blotting and densitometric analyses of APOA expression in whole cell lysates from hepatocytes treated for 24 hours with increasing concentrations of $C A$ (expressed as mean \pm SD relative to controls; ${ }^{*} P<0.05$ ). (D) Primary hepatocytes were treated with GW4064 (5 $\mu \mathrm{M})$ for 24 hours and analyzed for APOA mRNA levels by real-time quantitative PCR. These data are presented as mean \pm SEM of 3 independent experiments $\left({ }^{\star \star} P \leq 0.01\right)$. (E) Western blotting and densitometric analyses of APOA expression in whole cell lysates from hepatocytes treated for 24 hours with GW4064 (5 $\mu \mathrm{M})$ (expressed as mean \pm SD relative to controls; $\left.{ }^{* \star} P \leq 0.01\right)$.

FXR bound as a monomer to the radiolabeled probe containing a wild-type DR-1 element (DR-1 WT) (Figure 6A, lanes 7 and 8) but not to the probe carrying the mutated DR-1 element (DR-1 M2) (Figure 6A, lanes 11 and 12). Formation of the FXR-DNA complex was specifically competed by cold DR- $1 \mathrm{WT}$ probe (Figure $6 \mathrm{~B}$, lanes 3-5), whereas the DR-1 M2 probe did not compete (Figure 6B, lane 6). Binding of FXR to the DR-1 WT probe was also competed by a cold IR-1 probe (Figure 6B, lane 7); notably, the cold IR-1 and cold DR-1 WT probes competed with a similar efficiency for the labeled DR-1 WT oligo. These results indicated that FXR binds specifically to the DR-1 site of human APOA promoter.

FXR competes for HNF4 $\alpha$ binding to the DR-1 element. DR- 1 elements have been shown to function as HNF $4 \alpha$ response elements (45). In order to investigate the regulation of $A P O A$ gene expression by $\mathrm{HNF} 4 \alpha$, we overexpressed $H N F 4 \alpha$ in cultured primary hepatocytes and studied the expression of the human APOA gene. As shown in Figure 7A, adenovirus-mediated overexpression of $H N F 4 \alpha$ in mouse primary hepatocytes from $\operatorname{tg}-A P O A$ mice dose dependently induced the expression of APOA mRNA levels compared with LacZ-transfected cells.

Next, we studied the effect of HNF $4 \alpha$ overexpression on the activity of the hAPOA $-1,952 /+52$ promoter. As shown in Figure 7B, overexpression of HNF4 $\alpha$ in HepG 2 cells dose dependently transactivated the human $A P O A$ promoter. However, additional cotransfection with FXR and/or CDCA treatment abolished the HNF4 $\alpha$-mediated transactivation (Figure 7C). This effect might be due to the occupan- cy of the HNF $4 \alpha$ response element (DR-1) by FXR. HNF $4 \alpha$-mediated transactivation of the $\mathrm{h} A P O A-1,952 /+52$ promoter was also observed in the nonhepatic cell line, COS-7, which neither expressed FXR nor HNF4 $\alpha$. Cotransfection with FXR alone or with FXR and CDCA significantly inhibited HNF $4 \alpha$ transactivation (Supplemental Figure 5), suggesting that FXR competes with HNF4 $\alpha$ for the DR-1 binding motif. We then performed a mobility shift assay to check whether HNF $4 \alpha$ binds to the DR-1 element at the -826-bp region of the human APOA promoter. HNF $4 \alpha$ bound to the radiolabeled probe containing DR-1 WT, and the protein-DNA complex was specifically competed by cold unlabeled WT probe (Figure 7D).

Taken together, these results suggest that this response element at -826 bp might be occupied by HNF4 $\alpha$ at the basal level, whereas bile acid activation leads to a switch of occupancy of this site by FXR.

To further confirm the interaction of FXR with the DR-1 element in the APOA promoter, in vivo ChIP experiments were performed with liver tissue isolated from $\operatorname{tg}-A P O A$ mice fed for 24 hours with normal chow or with chow containing $0.2 \%$ CA (Figure $7 \mathrm{E}$ ). In the control group, antibodies against $\mathrm{HNF} 4 \alpha$ precipitated DNA encompassing the DR-1 element (-826- to -814-bp region) in the APOA promoter. By contrast, $0.2 \%$-CA feeding led to occupancy of this response element by FXR alone without RXR. As a negative control, an equivalent amount of chromatin precipitated with a nonrelevant anti-IgG antibody did not result in any signal. The same DNA samples were PCR amplified by using primers covering the distal region of the $A P O A$ promoter, but no signal was 
A Full-length hAPOA -1952/+52

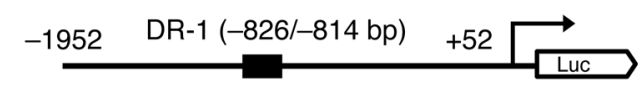

B

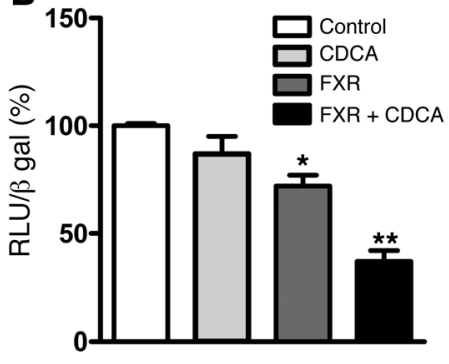

C

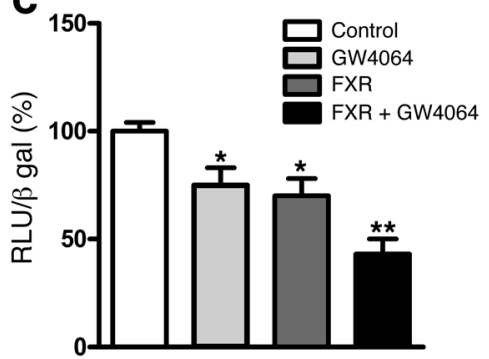

D
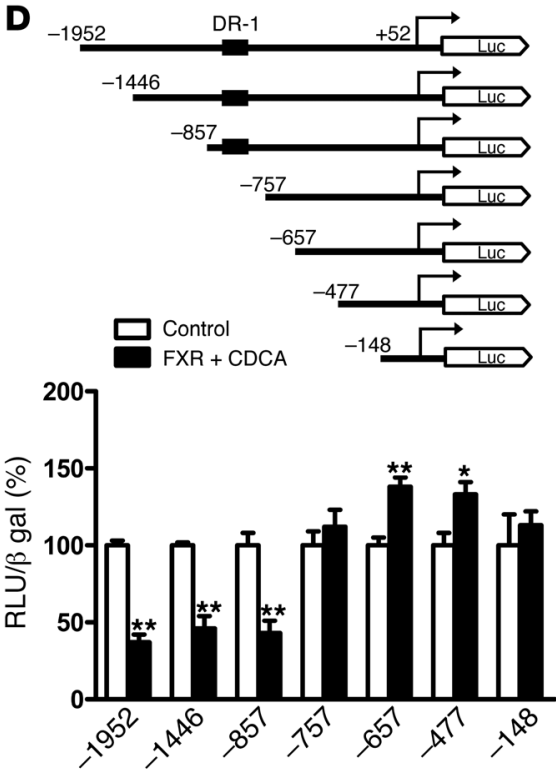

E

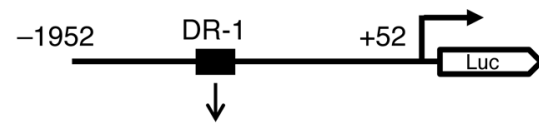

WT GGGGGGCCAACGCGCACGG

M1 GGGGatCCAACGCGCACGG

M2 GGGGGGCCAACatGCACGG

$\mathbf{F}$

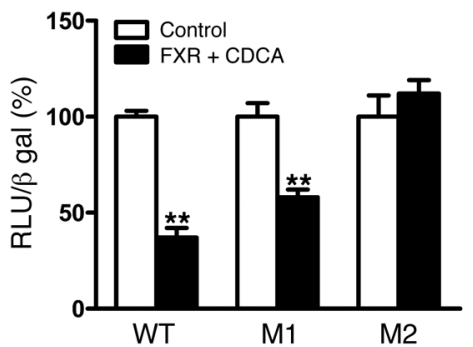

Figure 5

Bile acids and the nonsteroidal FXR agonist GW4064 downregulate human APOA promoter activity via FXR. (A) Scheme of the full-length hAPOA -1,952/+52 promoter-driven luciferase reporter system. (B and C) HepG2 cells were transfected with the hAPOA -1,952/+52 promoter reporter plasmid $(150 \mathrm{ng}$ ) in the presence of either the pcDNA3 (control) or FXR expression vector (150 ng). Cells were subsequently treated with CDCA $(100 \mu \mathrm{M})$, GW4064 $(500 \mathrm{nM})$, or vehicle for 36 hours. Values are normalized to internal control $\beta$-galactosidase and expressed as percentages. Transfections were performed in triplicates, and each experiment was repeated at least 3 times. (D) Scheme of the deletion constructs of the human $A P O A$ promoter used in the luciferase reporter assay. HepG2 cells were transfected with the indicated human $A P O A$ promoter reporter plasmids $(150 \mathrm{ng}$ ) in the presence of pcDNA3 empty or FXR expression vector (150 ng). Cells were then treated with CDCA $(100 \mu \mathrm{M})$ or vehicle for 36 hours. Values are normalized to internal control $\beta$-galactosidase activity. (E) Scheme showing wild-type and mutant sequences. Mutations are indicated in bold lowercase letters. Underlined letters define the DR-1 element. (F) Mutational analysis of the human APOA promoter. HepG2 cells were transfected with the wild-type and mutant (M1, M2) human APOA promoter reporter plasmids in the presence of pcDNA3 empty or FXR containing expression vector $(150 \mathrm{ng})$. Cells were then treated with CDCA (100 $\mu \mathrm{M})$ or vehicle for 36 hours. Values are normalized to $\beta$-galactosidase activity and expressed as percentages. Data are presented as mean $\pm \operatorname{SD}\left({ }^{* *} P \leq 0.01,{ }^{*} P<0.05\right)$.

observed, whereas $0.2 \%$-CA feeding increased the occupancy of both FXR and RXR to the Shp promoter.

Taken together, these results prove that the DR-1 element at the -826- to -814-bp region of the human APOA promoter could mediate the FXR repression of APOA transcription by a competition between FXR and HNF4 $\alpha$ (Supplemental Figure 7).

\section{Discussion}

Meta-analyses from prospective and epidemiological studies demonstrated an association of elevated plasma Lp(a) levels with an increased risk for ischemic heart diseases and stroke (7-11). Lp(a) is causally associated with an increased risk for myocardial infarction and reported to increase the likelihood for major adverse cardiovascular events when plasma Lp(a) levels exceed $30 \mathrm{mg} / \mathrm{dl}$ by 2.3 fold $(9,46)$. Therefore, unraveling molecular and pharmacological factors reducing Lp(a) constitutes a novel goal, with important therapeutic and pharmacological consequences in human population. In this study, we identified the bile acid-activated receptor FXR as a major repressor of Lp(a) levels in patients and mice having high bile acid levels. Notably, therapeutic normalization of bile acid concentrations lead to increased plasma Lp(a) levels. Similarly, bile duct ligation in trans- genic $A P O A$ mice virtually abrogated $A P O A$ expression. Therefore, we hypothesized that high intrahepatic bile acid could suppress $A P O A$ expression. In order to firmly demonstrate that bile acid-activated FXR was repressing $A P O A$ expression in a more physiological condition, we fed transgenic $A P O A$ and $F x r^{-1}$ transgenic $A P O A$ mice with bile acids. Bile acid feeding lowered APOA plasma concentration as well as gene expression and protein levels in transgenic $A P O A$ mice, an effect abolished in $\mathrm{Fxr}^{-/-}$transgenic APOA mice. Furthermore, in vitro activation of FXR by bile acids or a nonsteroidal FXR agonist lowered APOA gene expression in a time and dose-dependent manner, due to a transcriptional mechanism.

In normal individuals, plasma $\mathrm{Lp}(\mathrm{a})$ levels have been shown to correlate significantly with the synthesis rate of $\operatorname{APOA}(17,18)$ and appear to be minimally affected by its catabolism. Thus, pharmacological FXR activation could constitute a novel and promising approach to treat hyper-Lp(a) individuals and significantly reduce adverse coronary events in a high-risk population. Interestingly, novel FXR agonists were shown already to display antiatherosclerotic effects in mice (47) and to normalize dyslipidemia (48) in rodent models lacking APOA expression. It will therefore be of interest to measure Lp(a) in ongoing human clinical trials using FXR agonists 
A

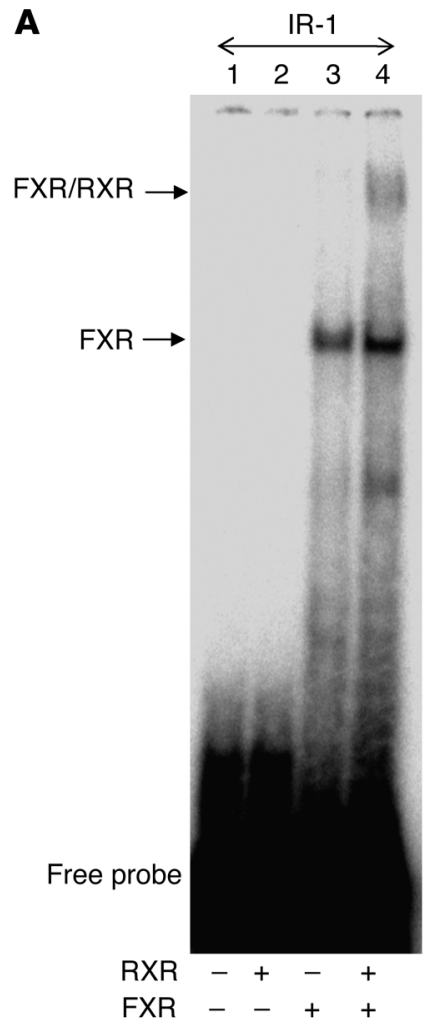

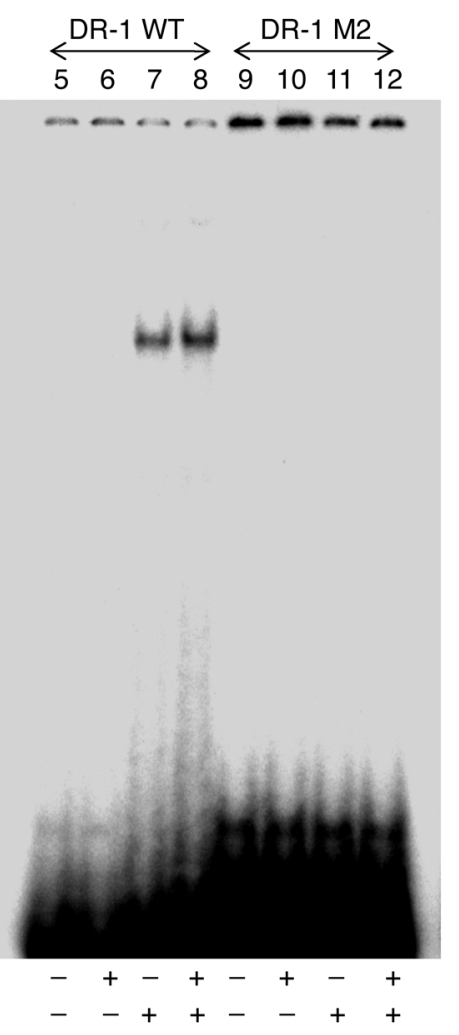

B

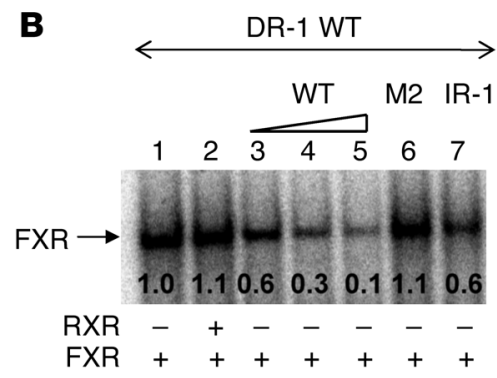

\section{Figure 6}

FXR binds to the DR-1 element of the human APOA promoter as a monomer. (A) EMSAs were performed with radiolabeled IR-1 consensus FXRE (lanes 1-4), DR-1 WT (lanes 5-8), and DR-1 M2 (lanes 9-12) probes using in vitro transcribed/translated RXR (lanes 2, 6, and 10), FXR (lanes 3, 7, and 11), both RXR and FXR (lanes 4, 8, and 12), or unprogrammed reticulocyte lysate (lanes 1, 5, and 9) as indicated. (B) Competition EMSAs on radiolabeled DR-1 WT probe were performed by adding 50-fold, 100-fold, 200-fold molar excess of the indicated cold DR-1 WT (lanes 3-5) and 50-fold molar excess of cold DR-1 M2 (lane 6) and IR-1 (lane 7) probes. Numbering indicates relative intensity of the bands.

such as INT-747. Bile acid binding resins, probably by depleting FXR ligand and therefore lowering FXR activation, were shown to reduce the incidence of coronary disease (49), due to the lowering of cholesterol and glucosuria (50). Novel resins with higher bile acid affinity, specificity, and binding capacity are currently available and constitute a safe therapeutic option, either in combination with HMGCoA reductase inhibitors (statins) or in statin-resistant patients. However, our results allude to the fact that resins and intestinal bile acid uptake inhibitors should be carefully monitored in a patient population with dyslipidemia and potentially elevated Lp(a). Conversely, introducing $\mathrm{Lp}(\mathrm{a})$ as a screening parameter could lead to improved resins without side effects, with even more cardiovascular protective.

FXR was found to directly repress APOA promoter activity by binding to a DR-1 site shared with $\mathrm{HNF} 4 \alpha$, leading to suppression of transcription. Several molecular regulators were found to bind to and modulate the promoter region of $A P O A$. These include binding sites for HNF1, HNF4 $\alpha$, RXR, and LINE among others $(51,52)$. FXR is highly expressed in the liver and was found to bind to IR-1 response elements in promoters as a heterodimer with RXR as well as to various DR elements (24), thereby transactivating cognate target genes. In addition, FXR can bind monomeric response elements and hence directly repress gene transcription (24-27). Recently, the location and sequence of FXRE was systematically studied via ChIP and sequencing (53). In this work, Chong et al. identified 1,656 binding sites, including $10 \%$ located in the proxi- mal $2 \mathrm{~kb}$ of the promoter. Moreover, up to $25 \%$ of these FXREs were not classical IR-1. In our study, by combining, reporter assays, site-directed mutagenesis, EMSA, and ChIP, we unambiguously identified a DR-1 located at -826-bp upstream of the transcription start site as what we believe to be a new negative FXRE in the promoter of APOA. This site is therefore compatible with the architecture of a bona fide FXRE. Since Chong et al. used a mouse liver not expressing APOA chromatin-enriched material, our response element could not be found in their database. However, the DR-1 located at the -826- to -814-bp region was found to be bound and activated by $\mathrm{HNF} 4 \alpha$ as shown by transfection, EMSA, and ChIP. In addition, HNF $4 \alpha$ was competitively displaced by FXR, as demonstrated in Figure 7E. HNF $4 \alpha$ is well known to be involved in lipid, glucose, and bile acid homeostasis (54). A competition between FXR and HNF $4 \alpha$ was previously found in the promoter of APOCIII $(24,43,44)$. It is therefore tempting to speculate that the balance between FXR and HNF $4 \alpha$ binding on gene promoters could coordinate a network of genes involved in lipid homeostasis (Supplemental Figure 7). The precise mechanism for this suppression, including the events involved in a nonproductive FXR binding to a response element, requires additional studies.

FXR also transactivates mouse Fgf15, a gene that is expressed almost exclusively in the terminal ileum, and its human ortholog, FGF19, a gene that is expressed in the small intestine as well as in the liver. FGF15/19 signals from intestine to the liver to repress 


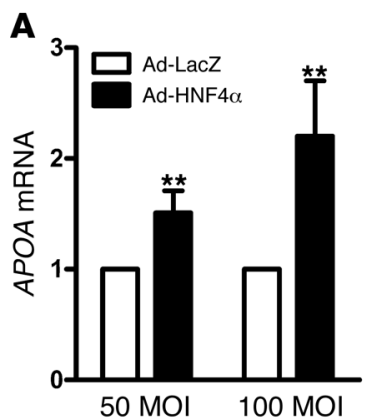

D
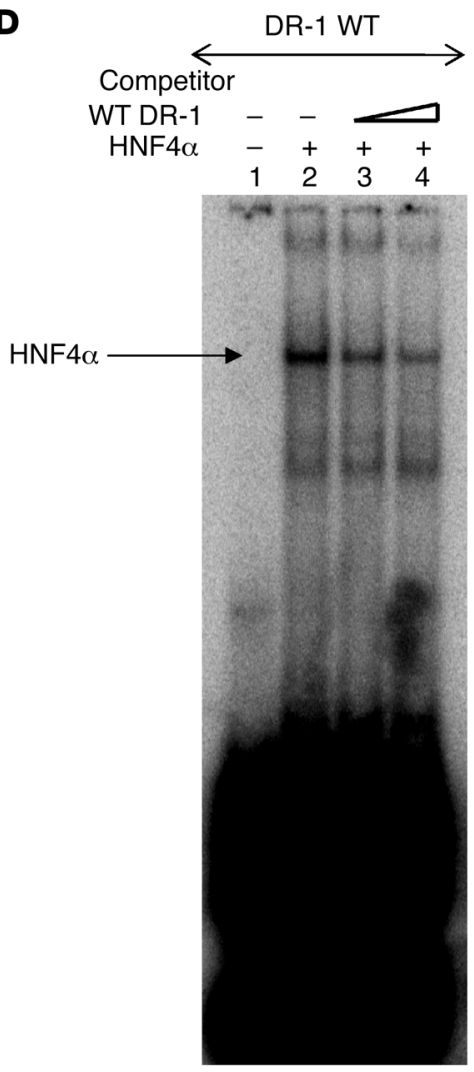

B

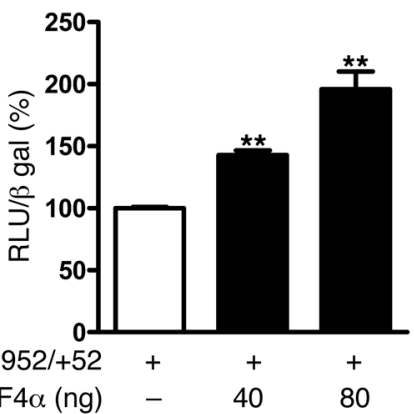

C

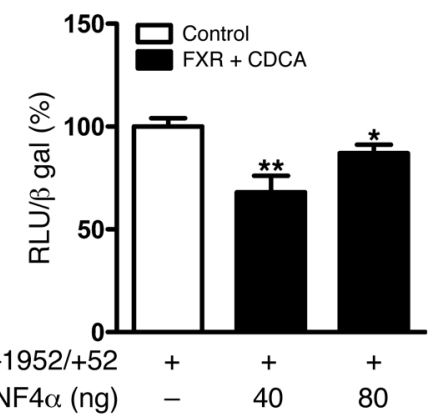

$\mathbf{E}$

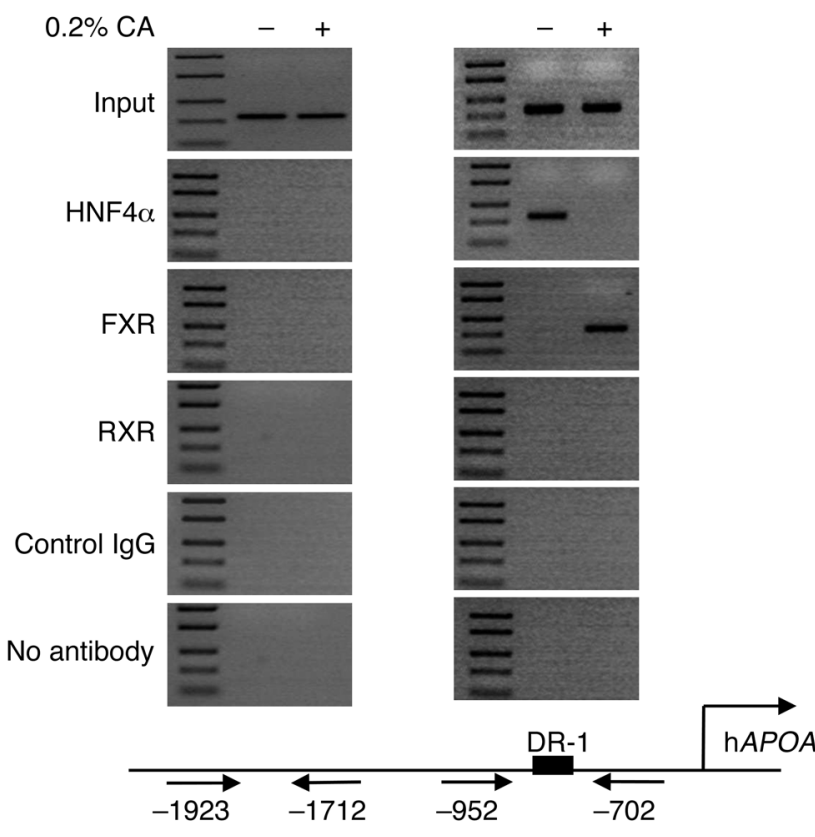

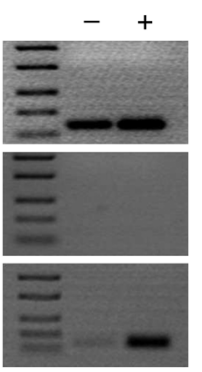
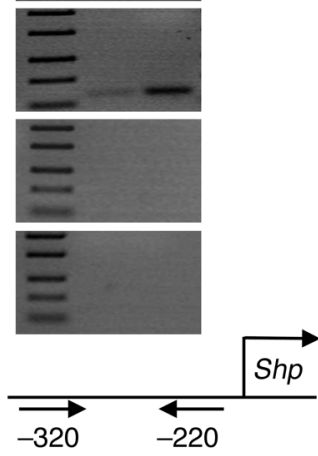

\section{hAPOA DR-1 WT GGGGGGCAACGCGCÁCGG}

\section{Figure 7}

Effects of hepatocyte nuclear factor HNF4 $\alpha$ overexpression on human APOA. (A) Primary mouse hepatocytes were infected with either adenovirus coding for $\beta$-galactosidase (Ad-LacZ) or human HNF4A (Ad-HNF4 $\alpha$ ). Total RNA was extracted, and gene expression was measured by real-time quantitative PCR. Data represent mean \pm SEM. ( $\left.{ }^{* *} P \leq 0.01\right)$. (B) HepG2 cells were transfected with the $\mathrm{h} A P O A-1,952 /+52$ reporter plasmid (150 ng) in the presence of increasing amounts of HNF4 $\alpha$ expression vector. Values represent mean $\pm \mathrm{SD}\left({ }^{\star \star} P \leq 0.01\right)$. (C) HepG2 cells were transfected with the hAPOA $-1,952 /+52$ reporter plasmid in the presence or absence of FXR and HNF $4 \alpha$. Cells were then treated with CDCA $(100 \mu \mathrm{M})$ or vehicle for 36 hours. Values are normalized to internal control $\beta$-galactosidase and expressed as percentages. Values represent mean $\pm \mathrm{SD}\left({ }^{* *} P \leq 0.01,{ }^{*} P<0.05\right)$. (D) HNF4 $\alpha$ binds to the DR-1 motif in the human APOA promoter. EMSAs with end-labeled DR-1 WT probe using in vitro transcribed/translated HNF4 $\alpha$ (lanes 2). Competition analysis was performed by adding 50-fold (lane 3) and 100-fold (lane 4) molar excess of the indicated cold DR-1 WT probe. Underlined letters indicate the DR-1 element. (E) tg-APOA mice were fed normal chow or $0.2 \%$ CA chow for 24 hours, and livers were collected for ChIP analyses. For ChIP assay, sheared chromatin was immunoprecipitated with the indicated antibodies. The final DNA extractions were amplified by PCR using primer pairs covering the distal region and the DR-1 motif of the APOA gene promoter. As a positive control for FXR/RXR binding, the Shp gene promoter was amplified by PCR.

the transcription of key enzymes of bile acid biosynthesis $(34,55)$. Notably, FXR activation efficiently repressed $A P O A$ in vitro in primary mouse hepatocytes that do not express Fgf15, indicating that FXR can regulate the APOA gene in an FGF15/19-independent manner. Further studies will be required to clarify a possible additional role of FGF15/19 in APOA gene repression.

In addition, FXR can indirectly modulate gene expression via the induction of Shp in the liver (31). Although SHP is a transcriptional 
repressor, it has no DNA binding motif (56) but interacts with several nuclear receptors, such as LRH- 1 or $\mathrm{HNF} 4 \alpha$, thereby interfering with gene transcription. Recently, the SHP/LRH-1/CYP7A1 signaling pathway was disproved, and LRH-1 was identified as a master regulator of Cyp $8 b 1(57,58)$. Since SHP is able to interact in vitro with multiple partners, the identification of the actual SHP targets is still an open quest. Our transgenic APOA mice fed with CA or primary hepatocytes incubated with FXR activators were found to have more Shp and less APOA gene expression. We therefore wondered whether $S h p$ induction could repress APOA. However, dose response transfection experiments with SHP expression plasmid showed that SHP did not repress and instead increased the APOA promoter activity in HepG2 as well as in COS-7 cells (Supplemental Figure 6). Conversely, FXR directly repressed APOA promoter activity by binding to a DR-1 also recognized by HNF4 $\alpha$. This was verified by ChIP assay, which impressively confirmed that the DR-1 element at the -826 - to -814-bp region of the APOA promoter is occupied by $\mathrm{HNF} 4 \alpha$, whereas CA activation leads to a switch of occupancy of the site by FXR (Figure 7E). Taken together, our data suggest that SHP does not regulate the APOA promoter in contrast to FXR.

In view of the present results, FXR agonist could constitute a new therapeutic avenue to treat hyper-Lp(a) states and may be useful in the treatment of atherosclerotic disease and myocardial infarction. In addition, these results suggest that present and future FXR partial agonists, also called bile acid receptor modulator (BARM), have to be monitored for possible adverse effects on plasma Lp(a) levels in human clinical trials.

\section{Methods}

Chemicals. CA and CDCA were purchased from Sigma-Aldrich. GW4064 was purchased from Tocris Bioscience. Collagenase was purchased from Worthington Biochemical Corporation.

Patients. Patients suffering from obstructive jaundice due to gallstones or malignancy were studied for markers of biliary obstruction and plasma $\mathrm{Lp}$ (a) concentrations. Blood of patients referred to surgery or endoscopy was analyzed immediately for plasma levels of Lp(a), bilirubin, total bile acids, and LP-X. After appropriate treatment, reversal of jaundice, and normalization of plasma bilirubin, plasma Lp(a) levels were measured again. All human studies were approved by the ethical committee of the Medical University of Graz and were performed in accordance with the Helsinki Declaration. Informed consent was received from all patients or their parents for drawing extra blood to perform lipid and lipoprotein analyses.

Analysis of plasma parameters and $L p(a)$ in patients. Lipids from human plasma were measured enzymatically using the assay kits from Roche Diagnostics. Lp(a) was quantified by an in-house DELFIA method. The preparation of $\mathrm{LP}(\mathrm{a})$ and $\mathrm{APOA}$ and the standardization of the $\mathrm{LP}(\mathrm{a})$ assay have been described in detail previously (59). The determination of APOA isoforms was performed by Western blotting as described previously (60). LP-X was measured by standard methods (61). Total plasma bile acids were measured enzymatically (62).

Animal experiments. All animal experiments were performed after approval of the protocol by the Austrian Federal Ministry of Science and Research, Division of Genetic Engineering and Animal Experiments (Vienna, Austria). Fxr $/$ mice (28) were backcrossed for 5 generations with tg-APOA mice, carrying a $110-\mathrm{kb}$ human $A P O A$ gene surrounded by more than $60-\mathrm{kb} 5^{\prime}$ and 3 '-flanking DNA in the YAC (63). Mice were hosted under a standard 12-hour-light/12-hour-dark cycle and fed standard rodent chow diet and water ad libitum. Female mice, between 10 and 12 weeks old, were used in all the experiments. For feeding studies, $\operatorname{tg}-A P O A(n=8)$ and $\operatorname{tg}-A P O A / F x r^{\prime-}$ mice $(n=8)$ expressing the human APOA were divided into 2 groups. Ani- mals were randomized based on plasma APOA levels. One group received a normal rodent chow diet (control), whereas the other group received the same diet supplemented with $0.2 \%(\mathrm{w} / \mathrm{w}$ ) CA for 5 days. At sacrifice, mice were fasted for 4 hours before blood samples were collected. Liver and ileum samples were harvested and stored at $-80^{\circ} \mathrm{C}$ until further analysis. For the ChIP assay, female tg-APOA mice $(n=3)$ were fed with either normal chow (control group) or chow with $0.2 \%$ CA for 24 hours. Freshly isolated liver tissue was pooled and used to isolate chromatin for immunoprecipitation.

Plasma lipid parameters in mice. Blood was collected by retro-orbital bleeding and EDTA plasma was prepared within 20 minutes. Plasma concentrations of APOA were measured enzymatically by an in-house DELFIA method. Plasma triglyceride (DiaSys) and total cholesterol concentrations (Greiner Diagnostics AG) were determined enzymatically according to the manufacturer's protocols.

$C B D L$. Twelve-week-old female tg-APOA mice ( $n=3-4$ per group) and $\operatorname{tg}-A P O A / F x r^{-}$mice ( $n=3$ per group) were subjected to CBDL as described previously (64). In brief, the common bile duct was ligated close to the liver hilus, immediately below the bifurcation, and dissected between the ligatures. Sham-operated animals were subjected to the same surgical procedure but without ligation of the common bile duct. Sera and livers were collected for analysis 3 days after surgery. Liver tissue was frozen in liquid nitrogen for further RNA preparations. Serum was stored at $-80^{\circ} \mathrm{C}$ until analysis. Serum alanine aminotransferase, aspartate aminotransferase, alkaline phosphatase levels, and bilirubin were determined by routine testing on a Hitachi 917 analyzer (Boehringer Mannheim), as measures of the degree of cholestasis. Total serum bile acid levels were determined enzymatically using the Bile Acid Kit (Ecoline S+, DiaSys Diagnostic Systems).

Cell cultures. Mouse primary hepatocytes from tg-APOA mice were prepared and cultured as described previously (65), with minor modifications. The mouse liver was perfused with collagenase solution, and liver cells were collected. After filtration and centrifugation, the isolated hepatocytes were resuspended in DMEM (Invitrogen) supplemented with 20\% (v/v) FCS (Sigma-Aldrich), 100 units $/ \mathrm{ml}$ penicillin, and 100 units/ml streptomycin and placed in 6-well collagen-coated plates (BD Biosciences) at a density of $1 \times 10^{5}$ cells/well at $37^{\circ} \mathrm{C}$ in an atmosphere of $5 \% \mathrm{CO}_{2}$ for 4 hours. Thereafter, cells were cultured in DMEM supplemented with $10 \%$ FCS and $100 \mathrm{units} / \mathrm{ml}$ penicillin/streptomycin for 16 hours. Experiments were performed in serum-free DMEM supplemented with various concentrations of the FXR ligands CA and GW4064.

The HepG2 and COS7 cells were obtained from ATCC. The cells were maintained in DMEM containing 10\% FCS and 100 units $/ \mathrm{ml}$ penicillin/streptomycin.

$R N A$ extraction, reverse transcription, and real-time PCR. Total RNA from cells and mouse tissues was isolated using TRIzOL (Invitrogen) according to the manufacturer's protocol. Two micrograms of total RNA were reverse transcribed using the High-Capacity cDNA Reverse Transcription Kit (Applied Biosystems). Quantitative real-time PCR was performed on a Light Cycler 480 instrument (Roche Diagnostics), using the QuantiFast SYBR Green PCR Kit (Qiagen). Primer sequences are listed in Supplemental Table 3. The gene expression values were normalized to cyclophilin A (Ppia) as a housekeeping gene. The data were analyzed by the public domain program Relative Expression Software Tool (REST; http://www.gene-quantification. de/download.html\#rest) (66). Values are presented as mean \pm SEM.

Protein extraction and immunoblotting. Livers were homogenized or cells were lysed in an ice-cold RIPA buffer. The lysates were centrifuged $(12,000 \mathrm{~g})$ at $4{ }^{\circ} \mathrm{C}$ for 10 minutes, and the supernatant was collected. Protein was quantitated using the Bradford protein assay (Bio-Rad). Equivalent amounts of protein homogenates were resolved by SDS-PAGE, transferred to a nitrocellulose membrane, and probed with rabbit polyclonal antibodies to human APOA $(1: 1,250)$ and a monoclonal anti-mouse $\beta$-actin 
$(1: 2,000)$ (Santa Cruz Biotechnology Inc.). The immunoblots were visualized by the Pierce ECL Chemiluminescence Detection System (Thermo Scientific). Densitometric analysis of the gels was carried out using ImageJ software (http://rsbweb.nih.gov/ij/). Data are presented as mean \pm SD.

Adenoviral infection of primary mouse hepatocytes. Primary hepatocytes from $\operatorname{tg}-A P O A$ mice were isolated and maintained for 24 hours before infection with 50 and $100 \mathrm{MOI}$ of adenovirus encoding LacZ or human HNF4A in serum-free DMEM. After a 4-hour infection, the cells were incubated in DMEM supplemented with $10 \%$ FCS for 24 hours, followed by cell harvesting for RNA analysis.

Plasmids. Expression plasmids encoding hFXR (pcDNA3-FXR), hRXR $\alpha$ (pSG5-RXR), SHP (pCDM8-SHP), and HNF4 $\alpha$ (pSG5-HNF4 $\alpha$ ) were provided by Peter Young (Dupont, Oakley, California, USA), Philippe Lefebvre (Institut Pasteur de Lille, Lille, France), David D. Moore (Baylor College of Medicine, Houston, Texas, USA), and Mary C. Weiss (Institut Pasteur, Paris, France), respectively. The human APOA promoter construct (hAPOA -1,952/+52) was obtained by PCR amplification using human genomic DNA as a template. The PCR product was cloned into the pGL3 basic vector (Promega) as a MluI/BglII fragment to generate human APOA-Luc. (Primers used are as follows: for forward reaction, 5'-ACGCGTTCTGAGAGGGAGGTCAAAGTTTTC-3', and reverse reaction, 5'-AGATCTCTTGAGAAAGCCAGCCCCAAAGGT-3'.) All constructs were verified by DNA sequencing (LGC Genomics).

Transient transfection and reporter gene assays. HepG2 cells were plated in 24 -well plates over night before transfection. Cells at $60 \%-70 \%$ confluence were transiently transfected with the indicated reporter plasmid (150 ng), with or with out receptor expression plasmids (150 ng), using FuGENE 6 reagent (Roche Diagnostics) according to the manufacturer's instructions. $\beta$-Galactosidase expression plasmid was cotransfected to assess the transfection efficiency. After 12 hours of transfection, medium was changed, and cells were exposed to the ligands (CDCA [100 $\mu \mathrm{mol} / \mathrm{l}]$, GW4064 [500 nmol/1]) or vehicle. After 36 hours, cell extracts were prepared using passive lysis buffer (Promega) and assayed for luciferase and $\beta$-galactosidase activities using the Luciferase Assay System and the $\beta$-Galactosidase Enzyme Assay System, respectively (Promega). Luciferase activities were measured using Lumat LB9501 (Berthold) and normalized to $\beta$-galactosidase activities for each transfected well. For each experimental trial, wells were transfected in triplicate, and each well was assayed in duplicate. Data are presented as mean $\pm \mathrm{SD}$.

Site-directed mutagenesis. Mutagenesis was performed using the QuikChange Site-Directed Mutagenesis System (Stratagene), according to the manufacturer's manual. The mutants were verified by sequencing. The oligonucleotides M1 (5' - GAGGGTTGGAAGCAAGAGGGGatCCAACGCGCACGGG GAGGAAGC-3') and M2 (5'-GAAGCAAGAGGGGGGCCAACatGCACGGGGAGGAAGCATTTGGGCAG- $3^{\prime}$ ) were used to introduce mutations into the full-length $\mathrm{h} A P O A-1,952 /+52$. Mutated bases are indicated by bold, lowercase letters, and underlined letters define the DR-1 element.

EMSAs. Human FXR, RXR, and HNF4 $\alpha$ proteins were synthesized in vitro using the TNT T7 Quick Coupled Transcription/Translation System (Promega). The sense and antisense oligonucleotide probes of DR-1 WT (5'-AGGGGGGCCAACGCGCACGGG-3'), DR-1 M2 (5'-AGGGGGGCCAACatGCACGGG-3'), and a FXR IR-1 consensus response element-containing oligonucleotide (IR-1, 5'-GATCTCAAGAGGTCATTGACCTTTTTG-3') were annealed and radioactively labeled at the $5^{\prime}$ end using T4 polynucleotide kinase and $\gamma-{ }^{32} \mathrm{P}$-ATP (Hartmann Analytic GmbH) (mutated bases are indicated by bold, lowercase letters, and underlined letters define the IR-1 element). Unincorporated nucleotides were removed by using Micro Bio-Spin 6 Columns (Bio-Rad). In vitro translated proteins $(2.0 \mu \mathrm{l})$ were incubated for 20 minutes at room temperature in a total volume of $10 \mu \mathrm{l}$ with binding buffer (Gel Shift Assay System, Promega) before the labeled probe was added. Binding reactions were further incubated for $30 \mathrm{~min}$ utes and resolved by $6 \%$ nondenaturing polyacrylamide gel electrophoresis in $0.25 \mathrm{X}$ Tris-Borate-EDTA buffer at room temperature and $120 \mathrm{~V}$ for 3.5 hours. The gel was dried and exposed to an X-ray film. For competition experiments, unlabeled probes were included in the binding reaction at the indicated excess concentrations.

ChIP assay. The in vivo ChIP assay was performed with freshly isolated mouse liver tissue using the EpiQuik Tissue ChIP Kit (Epigentek) according to the manufacturer's instructions, with minor modifications. Liver tissue was fixed in formaldehyde for 12 minutes and then quenched for 5 minutes with glycine. The nuclei were extracted and sonicated to yield 500- to $1,000-\mathrm{bp}$ DNA fragments. Aliquots of sheared chromatin were then immunoprecipitated using $4 \mu \mathrm{g}$ anti-FXR (sc-13063; Santa Cruz Biotechnology Inc.), anti-RXR (sc-553; Santa Cruz Biotechnology Inc.), $2 \mu \mathrm{g}$ anti-HNF4 $\alpha$ antibody (sc-6556; Santa Cruz Biotechnology Inc.), or $1 \mu \mathrm{g}$ anti-IgG antibody. Nonprecipitated chromatin (input) was used as a positive control. DNA extractions were PCR amplified using the following flanking primers, and the PCR products were analyzed by agarose gel electrophoresis: DR-1 element in the APOA promoter (DR-1 ChIP forward, 5' TTGGCAGTGTTATTGGGAGAC 3'; DR-1 ChIP reverse, 5' ACAGGCAGTTCCATCACTCC $3^{\prime}$ ), distal region of the APOA promoter (distal ChIP forward, $5^{\prime}$ TCTCCCCTTCATGTTTCCAG $3^{\prime}$; distal ChIP reverse, 5' CCAGTGGCCGACATAGAGAT $3^{\prime}$ ), and Shp promoter (Shp ChIP forward, 5'GCCTGAGACCTTGGTGCCCTG 3'; Shp ChIP reverse, 5' CTGCCCACTGCCTGGATGC 3').

Statistics. Statistical analyses of the experiments were performed with GraphPad Prism 5.0. Two-tailed, unpaired Student's $t$ test was applied to determine statistical significance.

\section{Acknowledgments}

This work was supported by the Medical University of Graz (I. Chennamsetty and A. Baghdasaryan are funded by the PhD program "Molecular Medicine"), the Austrian Science Fund FWF (SFB-LIPOTOX F3004, F3008, and P19186), and the Austrian Federal Ministry of Science and Research (GEN-AU project Genomics of Lipid-associated Disorders - GOLD). The authors thank A. Ibovnik for excellent technical assistance.

Received for publication January 14, 2011, and accepted in revised form June 1, 2011.

Address correspondence to: Gert M. Kostner, Institute of Molecular Biology and Biochemistry, Center of Molecular Medicine, Medical University of Graz, 8010 Graz, Harrachgasse 21, Austria. Phone: 43.316.380.4202; Fax: 43.316.380.9615; E-mail: Gerhard. kostner@medunigraz.at.

\footnotetext{
1. Hobbs HH, White AL. Lipoprotein(a): intrigues and insights. Curr Opin Lipidol. 1999;10(3):225-236.

2. Kostner KM, Kostner GM. Lipoprotein(a): still an enigma? Curr Opin Lipidol. 2002;13(4):391-396.

3. Gaubatz JW, Heideman C, Gotto AM Jr, Morrisett JD, Dahlen GH. Human plasma lipoprotein [a]. Structural properties. J Biol Chem. 1983;258(7):4582-4589.
}

4. Kostner GM, Avogaro P, Cazzolato G, Marth E, Bittolo-Bon G, Qunici GB. Lipoprotein Lp(a) and the risk for myocardial infarction. Atherosclerosis. 1981;38(1-2):51-61.

5. Rhoads GG, Dahlen G, Berg K, Morton NE, Dannenberg AL. Lp(a) lipoprotein as a risk factor for myocardial infarction. JAMA. 1986;256(18):2540-2544.

6. Srinivasan SR, Dahlen GH, Jarpa RA, Webber LS,
Berenson GS. Racial (black-white) differences in serum lipoprotein (a) distribution and its relation to parental myocardial infarction in children. Bogalusa Heart Study. Circulation. 1991;84(1):160-167.

7. Tregouet DA, et al. Genome-wide haplotype association study identifies the SLC22A3-LPAL2-LPA gene cluster as a risk locus for coronary artery disease. Nat Genet. 2009;41(3):283-285. 
8. Clarke R, et al. Genetic variants associated with Lp(a) lipoprotein level and coronary disease. NEngl JMed. 2009;361(26):2518-2528.

9. Kamstrup PR, Tybjaerg-Hansen A, Steffensen R, Nordestgaard BG. Genetically elevated lipoprotein(a) and increased risk of myocardial infarction. JAMA. 2009;301(22):2331-2339.

10. Erqou S, et al. Apolipoprotein(a) isoforms and the risk of vascular disease: systematic review of 40 studies involving 58,000 participants. J Am Coll Cardiol. 2010;55(19):2160-2167.

11. Lanktree MB, Anand SS, Yusuf S, Hegele RA. Comprehensive analysis of genomic variation in the LPA locus and its relationship to plasma lipoprotein(a) in South Asians, Chinese, and European Caucasians. Circ Cardiovasc Genet. 2010;3(1):39-46.

12. Nordestgaard BG, et al. Lipoprotein(a) as a cardiovascular risk factor: current status. Eur Heart J 2010;31(23):2844-2853.

13. Lawn RM, Wade DP, Hammer RE, Chiesa G, Verstuyft JG, Rubin EM. Atherogenesis in transgenic mice expressing human apolipoprotein(a). Nature. 1992;360(6405):670-672.

14. Callow MJ, Verstuyft J, Tangirala R, Palinski W, Rubin EM. Atherogenesis in transgenic mice with human apolipoprotein B and lipoprotein (a). J Clin Invest. 1995;96(3):1639-1646.

15. Rouy D, Grailhe P, Nigon F, Chapman J, AnglesCano E. Lipoprotein(a) impairs generation of plasmin by fibrin-bound tissue-type plasminogen activator. In vitro studies in a plasma milieu. Arterioscler Thromb. 1991;11(3):629-638.

16. Kostner KM, Kostner GM. Therapy of hyper-Lp(a). Handb Exp Pharmacol. 2005;170(170):519-536.

17. Krempler F, Kostner GM, Bolzano K, Sandhofer F. Turnover of lipoprotein (a) in man. J Clin Invest. 1980;65(6):1483-1490.

18. Rader DJ, et al. The inverse association of plasma lipoprotein(a) concentrations with apolipoprotein(a) isoform size is not due to differences in $\mathrm{Lp}$ (a) catabolism but to differences in production rate. J Clin Invest. 1994;93(6):2758-2763.

19. Frank S, Gauster M, Strauss J, Hrzenjak A, Kostner GM. Adenovirus-mediated apo(a)-antisense-RNA expression efficiently inhibits apo(a) synthesis in vitro and in vivo. Gene Ther. 2001;8(6):425-430

20. Parks DJ, et al. Bile acids: natural ligands for an orphan nuclear receptor. Science. 1999; 284(5418):1365-1368.

21. Forman BM, et al. Identification of a nuclear receptor that is activated by farnesol metabolites. Cell. 1995;81(5):687-693.

22. Makishima $M$, et al. Identification of a nuclear receptor for bile acids. Science. 1999; 284(5418):1362-1365.

23. Wang H, Chen J, Hollister K, Sowers LC, Forman BM. Endogenous bile acids are ligands for the nuclear receptor FXR/BAR. Mol Cell. 1999; 3(5):543-553.

24. Laffitte BA, Kast HR, Nguyen CM, Zavacki AM, Moore DD, Edwards PA. Identification of the DNA binding specificity and potential target genes for the farnesoid X-activated receptor. J Biol Chem. 2000; 275(14):10638-10647.

25. Barbier O, et al. FXR induces the UGT2B4 enzyme in hepatocytes: a potential mechanism of negative feedback control of FXR activity. Gastroenterology. 2003;124(7):1926-1940.

26. Lu Y, Heydel JM, Li X, Bratton S, Lindblom T, Radominska-Pandya A. Lithocholic acid decreases expression of UGT2B7 in Caco-2 cells: a potential role for a negative farnesoid $\mathrm{X}$ receptor response element. Drug Metab Dispos. 2005;33(7):937-946.

27. Claudel T, et al. Bile acid-activated nuclear receptor FXR suppresses apolipoprotein A-I transcription via a negative FXR response element. J Clin Invest. 2002;109(7):961-971.
28. Sinal CJ, Tohkin M, Miyata M, Ward JM, Lambert G, Gonzalez FJ. Targeted disruption of the nuclear receptor FXR/BAR impairs bile acid and lipid homeostasis. Cell. 2000;102(6):731-744.

29. Kim I, et al. Differential regulation of bile acid homeostasis by the farnesoid $\mathrm{X}$ receptor in liver and intestine. J Lipid Res. 2007;48(12):2664-2672.

30. del Castillo-Olivares A, Gil G. Suppression of sterol 12alpha-hydroxylase transcription by the short heterodimer partner: insights into the repression mechanism. Nucleic Acids Res. 2001; 29(19):4035-4042.

31 . Goodwin B, et al. A regulatory cascade of the nuclear receptors FXR, SHP-1, and LRH-1 represses bile acid biosynthesis. Mol Cell. 2000;6(3):517-526.

32. Lu TT, et al. Molecular basis for feedback regulation of bile acid synthesis by nuclear receptors. $\mathrm{Mo}$ Cell. 2000;6(3):507-515.

33. Brendel C, Schoonjans K, Botrugno OA, Treuter E, Auwerx J. The small heterodimer partner interacts with the liver $\mathrm{X}$ receptor alpha and represses its transcriptional activity. Mol Endocrinol. 2002; 16(9):2065-2076

34. Inagaki $T$, et al. Fibroblast growth factor 15 functions as an enterohepatic signal to regulate bile acid homeostasis. Cell Metab. 2005;2(4):217-225.

35. Schuetz EG, et al. Disrupted bile acid homeostasis reveals an unexpected interaction among nuclear hormone receptors, transporters, and cytochrome P450. J Biol Chem. 2001;276(42):39411-39418.

36. Zollner G, et al. Role of nuclear bile acid receptor, FXR, in adaptive ABC transporter regulation by cholic and ursodeoxycholic acid in mouse liver, kidney, and intestine. J Hepatol. 2003;39(4):480-488

37. Davis RA, Miyake JH, Hui TY, Spann NJ. Regulation of cholesterol-7alpha-hydroxylase: BAREly missing a SHP. J Lipid Res. 2002;43(4):533-543.

38. Claudel T, Zollner G, Wagner M, Trauner M. Role of nuclear receptors for bile acid metabolism, bile secretion, cholestasis and gallstone disease [published online ahead of print December 29, 2010]. Biochim Biophys Acta. 2011;1812(8):867-878

39. StaudingerJL, et al. The nuclear receptor PXR is a lithocholic acid sensor that protects against liver toxicity. Proc Natl Acad Sci U S A. 2001;98(6):3369-3374.

40. Gupta S, Stravitz RT, Dent P, Hylemon PB. Down-regulation of cholesterol 7alpha-hydroxylase (CYP7A1) gene expression by bile acids in primary rat hepatocytes is mediated by the c-Jun $\mathrm{N}$-terminal kinase pathway. J Biol Chem. 2001; 276(19):15816-15822.

41. Cartharius K, et al. MatInspector and beyond: promoter analysis based on transcription factor binding sites. Bioinformatics. 2005;21(13):2933-2942.

42. Podvinec M, Kaufmann MR, Handschin C, Meyer UA. NUBIScan, an in silico approach for prediction of nuclear receptor response elements. MolEndocrinol. 2002;16(6):1269-1279.

43. Claudel T, et al. Farnesoid X receptor agonists suppress hepatic apolipoprotein CIII expression. Gastroenterology. 2003;125(2):544-555.

44. Anisfeld AM, et al. Syndecan-1 expression is regulated in an isoform-specific manner by the farnesoid- $X$ receptor. J Biol Chem. 2003;278(22):20420-20428.

45. Fraser JD, Martinez V, Straney R, Briggs MR. DNA binding and transcription activation specificity of hepatocyte nuclear factor 4. Nucleic Acids Res. 1998; 26(11):2702-2707.

46. Nicholls SJ, et al. Lipoprotein(a) levels and longterm cardiovascular risk in the contemporary era of statin therapy. J Lipid Res. 2010;51(10):3055-3061.

47. Miyazaki-Anzai S, Levi M, Kratzer A, Ting TC, Lewis LB, Miyazaki M. Farnesoid X receptor activation prevents the development of vascular calcification in ApoE-/- mice with chronic kidney disease. Circ Res. 2010;106(12):1807-1817.

48. Evans MJ, et al. A synthetic farnesoid X receptor
(FXR) agonist promotes cholesterol lowering in models of dyslipidemia. Am J Physiol Gastrointest Liver Physiol. 2009;296(3):G543-G552.

49. The Lipid Research Clinics Coronary Primary Prevention Trial results. I. Reduction in incidence of coronary heart disease. JAMA. 1984;251(3):351-364.

50. The Lipid Research Clinics Coronary Primary Prevention Trial results. II. The relationship of reduction in incidence of coronary heart disease to cholesterol lowering. JAMA. 1984;251(3):365-374.

51. Hixson JE, Jett C, Birnbaum S. Identification of promoter sequences in the $5^{\prime}$ untranslated region of the baboon apolipoprotein[a] gene. J Lipid Res. 1996;37(11):2324-2331.

52. Puckey LH, Knight BL. Sequence and functional changes in a putative enhancer region upstream of the apolipoprotein(a) gene. Atherosclerosis. 2003;166(1):119-127.

53. Chong HK, et al. Genome-wide interrogation of hepatic FXR reveals an asymmetric IR-1 motif and synergy with LRH-1. Nucleic Acids Res. 2010;38(18):6007-6017

54. Hayhurst GP, Lee YH, Lambert G, Ward JM, Gonzalez FJ. Hepatocyte nuclear factor 4alpha (nuclear receptor 2A1) is essential for maintenance of hepatic gene expression and lipid homeostasis. Mol Cell Biol. 2001;21(4):1393-1403.

55. Holt JA, et al. Definition of a novel growth factor-dependent signal cascade for the suppression of bile acid biosynthesis. Genes Dev. 2003;17(13):1581-1591.

56. Seol W, Choi HS, Moore DD. An orphan nuclear hormone receptor that lacks a DNA binding domain and heterodimerizes with other receptors. Science. 1996;272(5266):1336-1339.

57. Mataki C, et al. Compromised intestinal lipid absorption in mice with a liver-specific deficiency of liver receptor homolog 1. Mol Cell Biol. 2007;27(23):8330-8339.

58. Lee YK, et al. Liver receptor homolog-1 regulates bile acid homeostasis but is not essential for feedback regulation of bile acid synthesis. Mol Endocrinol. 2008;22(6):1345-1356.

59. Kostner GM, Ibovnik A, Holzer H, Grillhofer $H$. Preparation of a stable fresh frozen primary lipoprotein[a] (Lp[a]) standard. J Lipid Res. 1999; 40(12):2255-2263.

60. Kraft HG, Lingenhel A, Bader G, Kostner GM, Utermann G. The relative electrophoretic mobility of apo(a) isoforms depends on the gel system: proposal of a nomenclature for apo(a) phenotypes. Atherosclerosis. 1996;125(1):53-61.

61. Bos ES, van der Doelen AA, Denissen AE, Goverde BC, Magnani HN, Kostner GM. A novel assay for the quantitative determination of lipoprotein-X (LP-X) in serum. Clin Chim Acta. 1983;127(3):383-390.

62. Mashige F, Imai K, Osuga T. A simple and sensitive assay of total serum bile acids. Clin Chim Acta. 1976;70(1):79-86

63. Frazer KA, Narla G, Zhang JL, Rubin EM. The apolipoprotein(a) gene is regulated by sex hormones and acute-phase inducers in YAC transgenic mice. Nat Genet. 1995;9(4):424-431.

64 . Wagner $\mathrm{M}$, et al. Role of farnesoid X receptor in determining hepatic $\mathrm{ABC}$ transporter expression and liver injury in bile duct-ligated mice. Gastroenterology. 2003;125(3):825-838.

65. Salonpaa P, Pelkonen O, Kojo A, Pasanen M, Negishi M, Raunio H. Cytochrome P4502A5 expression and inducibility by phenobarbital is modulated by cAMP in mouse primary hepatocytes. Biochem Biophys Res Commun. 1994;205(1):631-637.

66. Pfaffl MW, Horgan GW, Dempfle L. Relative expression software tool (REST) for group-wise comparison and statistical analysis of relative expression results in real-time PCR. Nucleic Acids Res. 2002;30(9):e36. 